\title{
Communicative Development in a Game Context
}

\author{
Maria Thereza C. C. de Souza, Ana Lucia Petty \\ University of Sao Paulo, Sao Paulo, Brazil \\ Email:mtdesouza@usp.br
}

How to cite this paper: de Souza, M. T. C. C., \& Petty, A. L. (2017). Communicative Development in a Game Context. Psychology, 8, 246-257.

http://dx.doi.org/10.4236/psych.2017.82014

Received: November 3, 2016

Accepted: January 20, 2017

Published: January 23, 2017

Copyright $\odot 2017$ by authors and Scientific Research Publishing Inc. This work is licensed under the Creative Commons Attribution International License (CC BY 4.0).

http://creativecommons.org/licenses/by/4.0/

\begin{abstract}
This report is a short overview of an intervention program in which communicative development in a game context is focused. Mastering languages and different ways of communication are indicators of cognitive development. These are some of the goals of the intervention program held at the Laboratory of Studies about Development and Learning (Institute of Psychology) to help children from the fundamental school with learning difficulties develop affective, cognitive, motor and social attitudes, in a context of problem-solving situations with games. As a consequence, they improve competence to express and interpret more adequately, as well as discuss strategies and solve different challenges, regarding the capacity of learning from others and enhancing language skills. To observe children playing communicative games allows to analyze how they think and act, which generates important information to intervene in pro of changing the attitudes that do not work in favour of the learning and developing processes. Analysis was made from data registered on records, and six children who participated at the program during three semesters were described for illustrative purpose. It indicates that this context, in which narratives are produced and where there is adult mediation, contributes to help them modify inadequate attitudes and improve the domain of different languages, expanding the repertoire of communication.
\end{abstract}

\section{Keywords}

Communication, Playing Games, Intervention

\section{Introduction}

This paper aims at illustrating a successful experience held at the Laboratory of Studies about Development and Learning (Institute of Psychology, University of Sao Paulo). In this context, games with rules are used in favour of helping children with learning disabilities develop reasoning and adequate attitudes. As a 
consequence, they improve skills to master languages and different ways of communicating, which are important indicators of social and cognitive development. The genetic epistemology brings about relevant contribution to discuss why, how and when language appears in human development, being essential to build up communicative skills. In "Psychology of the child", Piaget and Inhelder (1968) have described many aspects that explain the mental growth, from birth until adolescence, being especially concerned about how children act, feel, socialize and think. They state that the semiotic function is a fundamental function to the development process, which allows the child to represent objects, events and concepts. It starts with imitation and develops into symbolic games, drawing, mental images, memories and language, being the latter used to express thoughts, but does not cause them, as it is meant to communicate. The language acquisition is essential to the construction of narratives and verbal representations (Piaget, 1964). The former enables the child to reconstitute past actions and the latter, to anticipate future actions. Being so, a more effective communication is the most evident consequence, stimulating the expansion of social and cognitive development. From this moment on, it is possible to observe important progress and qualitative changes in communication, as the child becomes able not only to exchange ideas, using logical resources to explain thoughts and procedures, but also to argue and discuss considering the real world as reference, becoming more independent from the symbolic explanations related to personal impressions.

Taking interindividual relations into consideration, there is a remarkable difference to be noticed, which is the possibility to act according to established rules, which allows the child to cooperate and play games with rules. In this process, learning from peers, respecting other points of view and a growth in autonomy are also attitudes that characterize progresses in the realm of communicative development. Playing games stimulates all sort of competences related to affective, motor, social and intellectual activities (De Souza \& Petty et al., 2002; Huizinga, 1938; Caillois, 1958; Chateau, 1955; Brenelli, 2005; Folquitto, 2013; Dell'Agli \& Brenelli, 2010; Petty \& Passos, 2005; Rossetti \& Missawa, 2008; Torres, 2001). The intervention program at the laboratory is directed to children from the Fundamental School, aged 7 - 11 years. Groups of twelve participants are seen for one hour every week, during the period of about three semesters. They take part in a game context with adult supervision and mediation, in which are challenged to play games and solve problems related to different experiences. The program presupposes practice and reflection, as well as evaluation and intervention, all done simultaneously during the sessions (De Souza \& Petty et al., 2014).

Many aspects can be analyzed from the game context, as it consists of a rich opportunity to understand children's attitudes and procedures to deal with problem-solving situations (Macedo, Petty, \& Passos, 1997, 2000, 2005; Petty \& De Souza, 2012). For this report, it will be discussed what is observed and how children proceed willing to express and interpret more adequately, building up body and face languages, graphic (drawing or writing) and oral communica- 
tions. They are invited to play games, discuss strategies and solve different challenges, all of them regarding the capacity of learning from others and enhancing language skills. Reading and writing also play important roles in the proposed activities.

Several games are used at the intervention program, aiming at stimulating children to develop communication and different manners to express themselves (Macedo, Petty, \& Passos, 2005). One of them is a very popular game in Brazil named "Image and Action". The purpose is to guess what was drawn by the player, saying the exact word written in a card. To start, the person who is designated to make the drawing has to get a card taken by chance among many and choose a word (there are 4 words in each card, representing objects, animals, places, actions). Then, he/she starts drawing and who says the correct word, shall be the next player. There is an hourglass to control the maximum time of the match (drawing and guessing). If no one discovers the right word, the player looses the game or, as we stimulate in the session, he/she asks for help and the selected peer will make suggestions on the drawing to make it clearer, adding details and/or eliminating the ones that hinder understanding. In this context, players experiment different aspects of the communication process, such as to speak, listen, send, share and receive information, comprehend meanings, identify images and significations. This particular game is somewhat simpler, but demands attention, will to be clear and at the same time, will to understand. It also presupposes group exposure which includes facing shyness and being humble to deal with unsuccessful situations, offering and receiving help.

Inspired by this game, and having noticed how it motivated children to overcome difficulties, we created a new one to expand the challenge. It is called "What is the Message" and instead of words, the cards have one sentence each. In this case, the player has to represent it, making drawings cut in two or three parts. By the end of the time set, players have to guess the meaning of the message and the winner is the one who proposes the most similar sentence, compared to the original. The sentences are simple, because the purpose is not to be good in drawing, but to make the others get the message (for example: "The boy kicked a ball and broke the window", "The monkey climbed the tree to get a banana", "The rocket went to planet Saturn", "Santa Claus entered the chimney"). Many aspects remain the same if compared to the "Image and Action" game in terms of communicating ideas and selecting details that best represent the contents, but in addition, the sense of narrative is introduced, considering there is a need to construct in the drawing context a link among subject, action and its consequences.

Another communicative game frequently used to analyze and intervene with children is named "The World Shuffle Book". It consists of 52 cards with images drawn on both sides and was originally produced by UNICEF. The purpose is to create a story based on a sequence of images that correspond to actions, objects, people or events. Each player picks one card at the time, chooses which side of it that will be considered and tells part of a story. The next one has to continue the 
narrative, considering what was said before, until the last player picks his/her card and has to finalize the story. Before the game starts, it is fundamental to get to know the cards. Thus, they should be put on a flat surface (table or floor) so that all participants can look at the images. It is also interesting to invite them to group the cards, aiming at observing animals, means of transportation, types of people and emotions, food and places.

The narratives can be proposed orally or in writing. The oral activity is a good start and it seems easy, but it turns to be quite challenging if the adult interventions demand careful and longer descriptions or more and broaden connections, as the children become familiar with the proposal. This practice instigates them to pay attention, connect information and expose themselves before peers. After many oral constructions, another important activity is to ask participants to write their own stories, picking for instance 4 or 5 cards in order to create a complete narrative. The written situation enables professionals to observe and discuss about some linguistic aspects such as orthography or grammar, making them relevant in the context it is produced. The sequence of actions can be a theme for analysis, mainly if the child cannot make him/herself clear. The contents or subjects elected to be part of the narrative also deserve special attention and can indicate preferences or give some hints of how does the child solve problems and put ideas together. At last, it is possible to figure out some aspects of space organization and type of letter. Many times we just give a sheet of paper without lines to allow each one use as it suits better.

When they finish writing, each text is read out loud, so that peers can share their own texts. At this point, it is interesting to suggest that the listeners try to guess what cards were used, considering how they were put in evidence. This is a very good means of transforming attention into a significant procedure. The reading moment also brings much information as it puts the reader into a prominent position, many times avoided at school, especially because some children feel uncomfortable to be in evidence and run the risk to make public mistakes. Moreover, with these three situations-oral, writing and reading-children with learning disabilities, in particular those related to language skills, find themselves willing to explore different ways of communicating, due to its playful characteristics. These game situations consist of a rich context to contribute in favour of children's communication development, acting in an environment that requires creative solutions and idea constructions. In all of them, interventions are made aiming at helping each child to overcome difficulties: either the particular ones related to the situation itself or attitudinal aspects related to this context. The latter are most important, due to their influence on child development as a whole, including team work, coordination of different information, consideration of other points of view, planning and anticipating, facing mistakes and search for solutions.

\section{Method}

For the period of three semesters children from the fundamental school played 
not only the games described above, but several ones, many of them demanding communication skills. To illustrate some benefits of the game context, among all participants, six children that have completed the three semesters of the program were taken into consideration. Researchers have used as reference two different sources of information. One was focused on the regularities taken out of the practice itself and the other was a registration form named "Observation Protocol". It is important to underline that no diagnostic occurs at the laboratory, because the children who take part in the intervention program were already diagnosed by school professionals. All of them were considered in need of help rather with learning difficulties and/or presenting inadequate behavior. This program held at the university contributes to improve their capacities including the communication skills.

\subsection{Information from the Practice}

For the last 25 years, professionals that see children at the laboratory have been using games and found out regularities regarding the contribution some of them bring to develop communication. The intervention program aims at providing a new context in which children must think about strategies and actions, facing different challenges presented in game situations. As a consequence, the game context brought about important information regarding children's play. It is important to underline that the aspects selected to discuss these games could be used as references to analyze similar ones.

\subsubsection{Image and Action-Analysis of Procedures}

This game demands constant regulation of actions, connected and in accordance to what the other players say trying to guess the word. Observers can analyze means of solution, starting with the player's knowledge when representing the selected word. The question "Does he/she know what is essential to appear in the drawing?" can be answered if it includes: a) the object itself that corresponds to the word; b) the context to which this object belongs; c) details that characterize the object; d) elements that contribute to focus on what has to be discovered. The presence or not of these aspects at least indicate some information about the child, such as if he/she can communicate using images, the quality of resources used and the flexibility to make changes on the drawing when no one chooses the right word. This game enables children to experiment communication as an on-going process, in which there is a will to express and, at the same time, to understand.

\subsubsection{What Is the Message-Questions to Learn from the Game Context}

There are many possibilities to learn about how children proceed while playing this game. One of them is to ask questions that can guide and help to collect information about the player, such as: a) does he/she plan how to represent the sentence cut in three parts? b) the chosen images help to understand the message? c) are there too many details, that might distract and hamper comprehension? d) when the other players use disconnected words with reference to the 
drawings, does he/she propose changes? e) is there a connection among parts and the whole? $\mathrm{f}$ ) what is the reaction if the group did not get the message? At the same time, it is possible to analyze the others players' attitudes, such as: cooperation in trying to understand what is drawn, interest in participating and type of contribution.

\subsubsection{The World's Shuffle Book-Aspects to Observe from the Situations}

The construction of narratives is a challenging process, which demands a strong will to participate. The oral activity is very rich and a growing progress can be noticed, as it advances from simply saying the word that represents the image of the card, to a more sophisticated introduction of it in the context, when more than one match is played. If the child is the last one to pick a card, he/she has to connect many parts of the story, considering what was already said and in addition, has to suggest an end to the story. Some procedures indicate what can be observed from the narrative creation. It can be as simple as naming the object on the card, or it can include description of details; association with experience; integration of cards and creation of connections, including as many cards as possible to improve the narrative. The written activity demands coordination of cards, but it brings about another important challenge that is to transform thoughts into ideas organized in a text. In this case, it is also possible to verify orthographic and grammatical aspects, as well as to discuss the construction of the story and the text structure, aiming at being clear enough to the readers.

\subsubsection{Inventory of Interventions}

To enhance and help children develop to broaden the capacity of expressing ideas demands adult's precise and constant interventions. There are many situations in which it is necessary to intervene in favour of the communication process in the game context. For example, a) if the child is too shy, he/she can just watch the others playing, or can choose a partner to represent both of them; b) if ideas do not come easily, adults can ask questions and/or suggest two possibilities for him/her pick one; c) if it does not work, it is possible to offer a new card, or to skip the turn until he/she identifies the right moment to introduce the card; d) if the narrative does not match with the rest of the story, it can be argued about the connection and what can be added to integrate; e) if the contribution is very poor, questions about the card usually help to elaborate a better narrative.

\subsection{Information from the Observation Protocol}

This record was created aiming at registering attitudes and procedures of each child while playing games with rules, and was focused on four moments: a) introducing the game; b) playing the game; c) dealing with conflicts and d) analyzing the experience. To get information about each moment there was a correspondent question, with alternatives about possible characteristics of the child being observed. It is important to emphasize that besides choosing the most suitable ones, it was also necessary to write an explanation to justify why they were chosen and what aspects of the child's behaviour were evident. The con- 
tents of each moment are described as follows:

\subsubsection{Introducing the Game}

The main question was: what were the predominant attitudes noticed before the match started? By the time the game and rules were set, it was possible to observe different reactions to the proposal. A child might have demonstrated attitudes, such as interest, initiative, promptness to begin or, on the other hand, tardiness, distraction, fear to face a new situation, and also impulsiveness or anxiety.

\subsubsection{Playing the Game}

During the match or trying to solve a challenge, what attitudes appeared more frequently? While playing the game, each child showed how he/she acted to achieve the established goals, what procedures were considered meaningful and enabled to follow the rules and what strategies were built willing to win. It was also interesting to notice if the child seemed autonomous, self-confident and searched for new solutions, or if he/she was easily distracted by opponents, did not invest in different strategies or needed constant adult help.

\subsubsection{Dealing with Conflicts}

What kind of attitudes predominated when there was an obstacle or conflict that had to be surpassed in order to succeed? During a match, players always have to deal with difficulties, related to cognitive challenges and/or social demands, developing attitudes in favour of good results. Reactions of all sorts are usually observed, from persistence and self-control to irritation and discomfort. In the game context it was also possible to notice if the child used different sources to achieve a goal or repeated the same mistakes and/or unsuccessful procedures trying to deal with a problem.

\subsubsection{Analyzing the Experience}

When the game was over, what was the player's view about his/her experience? Frequently there are conversations about the whole process, in which professionals question each one about difficulties, asking for explanations that justify winning or losing and what could be done the next time the game is played in order to avoid unsuccessful situations. Some children showed no interest in discussing the results, needing help to analyze and understand attitudes and procedures. Others felt happy to share the good results achieved and seemed more confident to face future challenges.

As already mentioned, this report took into consideration information collected from the experience and the observation protocols. Nevertheless, this analysis was based on the observation protocols, exclusively regarding attitudes related to the capacity of learning from others, dealing with problem-solving situations and enhancing language skills. That is to say, the focus was on moments c), which represented a conflict the child faced while playing the game, and $\mathrm{d}$ ), which indicated how he/she analyzed the experience. In both cases, the main point was to observe whether the child noticed inadequacy and remained 
the same, or if there were changes and awareness growth. A total of 24 records (4 per children) were analyzed, corresponding to the four different dates in which communication games were played.

\section{Results and Discussion}

Results indicate that many changes happened within the game context and put in evidence relevant reactions about the children. They were chosen to illustrate four moments of the process. Child 1 to Child 6 will be presented at the paragraphs below. It is necessary to take into consideration some important information: four attitudes were described at moment $\mathrm{c}$ (dealing with conflicts) and another four attitudes were observed at moment $d$ (analyzing the experience). They correspond to dates 1 to 4 : date 1 indicates initial attitudes; dates 2 and 3 refer to transition and date 4 indicates final attitudes. The process was studied and was analyzed as being positive, medium or negative, according to the reactions registered on the records. The positive attitude was interpreted as corresponding to progress and autonomy, the medium corresponded to progress with help, and the negative attitude was considered when no progress was observed.

Child 1 (GAB) showed the following attitudes when there was a conflict (moment $\mathrm{c}$ ): persistence on mistake, cheating to surpass error and facing the challenge at dates 3 and 4 . For the analysis (moment $d$ ), it started with a non perception of failure, changed to dealing with failure and finalized with satisfaction with result at dates 3 and 4 . For both moments, the process was considered positive.

Child 2 (PED) showed the following attitudes when there was a conflict (moment $c$ ): searching for strategies, searching for different strategies, facing challenges with help and facing challenges with persistence. For the analysis (moment d), it started with perception of mistakes, satisfaction with result, perception of mistakes and at date 4, more autonomy to play. For both moments, the process was considered positive.

Child 3 (NIC) showed the following attitudes when there was a conflict (moment c): no solution to problems, searching for different strategies, facing challenges and facing challenges with help. For the analysis (moment $d$ ), it started with dissatisfaction with result, satisfaction with result at dates 2 and 3 , and finalized with satisfaction and autonomy. For moment $c$, the process was considered medium and for moment $\mathrm{d}$, positive.

Child 4 (LUC) showed the following attitudes when there was a conflict (moment c): no strategies, persistence with no strategies, searching for strategies and persistence. For the analysis (moment d), it started with no interest to discuss the result, non perception of failure, satisfaction with result and at date 4 , need of help to discuss. For moment $c$, the process was considered positive and for moment d, medium.

Child 5 (CLE) showed the following attitudes when there was a conflict (moment c): no strategies, persistence to solve problem at dates 2 and 3 and persistence and solution. For the analysis (moment $\mathrm{d}$ ), it started with no interest to 
discuss result, need of help to discuss, satisfaction with result and finalized with satisfaction and help. For moment $c$, the process was considered positive and for moment d, medium.

Child 6 (DIO) showed the following attitudes when there was a conflict (moment c): difficulty to face problem, searching for strategies, persistence and facing the problem with help. For the analysis (moment d), it started with dissatisfaction with result, satisfaction with agitation, satisfaction with attention, satisfaction with confidence. For moment $\mathrm{c}$, the process was considered medium and for moment $\mathrm{d}$, positive.

As it is possible to verify, this description indicates that the game context in which narratives are produced and there is adult mediation, there are more positive results $(\mathrm{N}=8)$, than medium ones $(\mathrm{N}=4)$, and no negative results at all. The comparison was made among reactions registered from dates 1 to 4 , and aimed at noticing if there were changes at the end as the child played the games.

At moment $c$, in the beginning all children presented unsatisfactory procedures in dealing with conflicts, that is no perception of mistakes, no solution created, difficulty to develop strategies and even cheating to get rid of the problem (date 1). However, there were more positive reactions on the second and third days (dates 2 and 3), meaning willingness to face challenges. The variation of responses is probably due to differences in development, that is to say, each child had their own means to explore possible solutions. For example, even evaluated as showing a final positive result, Child 1 persisted on mistake and cheated before could face the challenge, while Child 2 already showed search for strategies since date 1 . The last situation at moment $\mathrm{c}$ (date 4) shows progress in most of the attitudes, which reinforces that the game context influences in favour of the construction of better procedures to deal with obstacles. To illustrate, it is possible to observe the reactions of Child 3 and Child 6: they presented no solution and difficulty to face the problem in the beginning, but were able to solve it with adult intervention. Even being evaluated as a final medium result, it can be considered interesting to observe the will to face conflicts and the initiative to ask for help, putting in evidence new attitudes.

Observing reactions that correspond to moment $d$, it is also possible to notice a progress in the capacity or interest to discuss and acknowledge what happened during the game situations. The initial reactions indicate no will to discuss and dissatisfaction with the results and only one child admitted perception of mistakes (date 1). The following two days (dates 2 and 3) brought about an important subject, related to autonomy, since some children needed help to discuss and analyze, having difficulty to perceive the situation as a whole. By the end of the process (date 4), most of the children were satisfied about their performances in the game context, indicating greater awareness and a more positive attitude when compared to the first day. There is a majority of final reactions evaluated as positive, as it can be noticed at Children 1, 2, 3 and 6. In these cases, it was possible to understand that they became more autonomous to self-analyze and change what was disturbing the game process as to achieve their goals. Child 4 
and Child 5 presented medium final result, indicating they still need support to discuss the game context.

Attitudes at conflict and analysis moments are important reactions to be under careful observation, due to their influence in children's behavior. It is possible to notice that there is a slight correspondence between dealing with conflicts and analyzing results. While the child is confused and unable to create solutions to deal with difficulties, he/she seems unwilling to discuss and avoids the conversation, knowing that it will lead to admit failure. As the process continues, new experiences occur at the same time as professionals offer constant support for him/her to build up better resources to solve problems. As a consequence of the intervention process, each child became more interested to discuss strategies and exchange ideas, which helped him/her overcome difficulties and feel satisfied with the results. The game context stimulated children to improve the domain of different languages and expand the repertoire of communication. All of them enhanced listening and comprehension abilities, learning from their own experiences and from peers. They also became more able to interpret and understand other points of view, as well as got more autonomous and confident to deal with challenges. It is important to underline that these observations are not strict to the children selected to illustrate the benefits of the intervention program, but can be expanded to every participant at the program.

\section{Conclusion}

The intervention program showed efficiency in helping children overcome their learning difficulties and inadequate attitudes when the activities were focused at games that challenged them to communicate. The program also contributes to develop motor, affective, cognitive and social skills, as children have to coordinate actions and movements, control impulsiveness, enhance reasoning and learn to share and respect other points of view. In the communication realm, the attitudes learnt generated better expression of ideas, feelings and sociability thus it occurred as a necessary and significant consequence. In the game context, it is always possible to choose between the quantitative and/or qualitative aspects to analyze. The quantitative aspect, for instance, may show if the mistakes were excessive and where they appeared more frequently. It also enables to identify how frequently and in what activities children failed or required more adult help. Nevertheless, in this particular report, researchers were more concerned about understanding qualitatively what was going wrong, aiming at creating interventions that could help children with learning disabilities overcome some of their communicative difficulties.

Intervention is a continuous process that includes at least three principles and they all corroborate to build up a formative evaluation context (Perrenoud, 1998). One is related to the procedures themselves, and children are stimulated to act in favour of dealing with mistakes, such as to find and correct them, compare strategies to pick the most suitable ones, reorganize ideas and enrich speaking and writing with new vocabulary. The other is due to broaden aware- 
ness, since children are invited to describe and justify their choices, analyze different texts and share successful procedures. The third principle presupposes the deepening of the understanding of attitudes and consequences, meaning evaluation of what has to be changed and what favours the learning and development processes, which contributes to more consistent cognitive and social-affective performances. The group also plays a fundamental part and interferes in the child's actions, contributing with the intervention context. This situation offers a powerful reference to show whether communication happened or not, and what was disrupting it. The child's reactions and procedures indicate what he/she needs to change, and where adult mediation can be more effective. Learning to self-analyze and build up inner resources to surpass difficulties is important attitude to be achieved, not only at the game context, but also at home and school. To sum up, communicative games seem to contribute in favour of many aspects related to speaking, reading, writing and interpreting, which are essential to the learning and development processes.

\section{Conflict of Interest}

The authors De Souza and Petty declare that there is no conflict of interest.

\section{References}

Brenelli, R. (2005). Uma proposta psicopedagógica com jogos de regras (Psychopedagogical Proposal with Games). In Sisto De Souza et al. (Orgs.). Atuação psicopedagógica e aprendizagem escolar (Psychopedagogical Performance and School Learning) (pp. 140-162). Petrópolis: Vozes. (In Portuguese)

Caillois, R. (1958). Os jogos e os homens-A máscara e a vertigem (Games and Mankind-Mask and Vertigo). Lisboa: Cotovia. (In Portuguese)

Chateau, J. (1955). O jogo e a criança (Games and the Child). São Paulo: Summus. (In Portuguese)

De Souza, M. T. C. C., Petty, A. L. et al. (2002). Assessing Game Activities: A Study with Brazilian Children. In J. Retschitzki, \& R. Haddad-Zubel (Eds.), Step by Step (pp. 183-190). Suisse: Editions Universitaires Fribourg.

De Souza, M. T. C. C., Petty, A. L. et al. (2014). Does Playing Games Contribute to Develop Better Attitudes? Psychology Research, 4, 301-309.

Dell'Agli, B., \& Brenelli, R. (2010). Dificuldades de aprendizagem: Analise das dimensões afetiva e cognitiva (Learning Difficulties: Affectivity and Cognitive Dimensions). In L. Caetano (Org.), Temas atuais para a formação de professores, contribuições da pesquisa piagetiana (Current Issues for Teacher Education, Contributions of Piaget's Research) (pp. 25-44). São Paulo: Paulinas. (In Portuguese)

Folquitto, C. T. F. (2013). Psychological Development and Intervention Strategies with Children with Attention Deficit Hyperactivity Disorder (ADHD). São Paulo: IPUSP. (In Portuguese) http://www.teses.usp.br/

Huizinga, J. (1938). Homo Ludens-O jogo como elemento da cultura (Homo LudensThe Cultural Influence). São Paulo: Perspectiva. (In Portuguese)

Macedo, L. De, Petty, A. L., \& Passos, N. C. (1997). 4 Cores, Senha e Dominó: Oficinas de jogos em uma perspectiva construtivista e psicopedagógica (4 Colors, Mastermind and Domino: Game-Workshops in a Constructivist and Psychopedagogical Perspective). São Paulo: Casa do Psicólogo. (In Portuguese) 
Macedo, L. De, Petty, A. L., \& Passos, N. C. (2000). Aprender com jogos e situaçôesproblema (Learning with Games and Problem-Solving Situations). Porto Alegre: Artmed. (In Portuguese)

Macedo, L. De, Petty, A. L., \& Passos, N. C. (2005). Os jogos e o lúdico na aprendizagem escolar (Games and the Ludic Aspect in School Learning). Porto Alegre: Artmed. (In Portuguese)

Perrenoud, P. (1998). Avaliação, da excelência à regulação das aprendizagens. (Evaluation, from Excellence to Regulation of Learning). Porto Alegre: Artmed. (In Portuguese)

Petty, A. L., \& De Souza, M. T. C. (2012). Executive Functions Development and Playing Games. US-China Education Review B, 9, 795-801.

Petty, A. L., \& Passos, N. C. (2005). Algumas reflexões sobre jogos de regras (Some Thoughts on Games with Rules). In Sisto De Souza et al. (Orgs.), Atuação psicopedagógica e aprendizagem escolar (Psychopedagogical Performance and School Learning). (pp. 163-174). Petrópolis: Vozes. (In Portuguese)

Piaget, J. (1964). Seis estudos de Psicologia (Six Studies of Psychology). Rio de Janeiro: Forense Universitária. (In French, 1994/1964)

Piaget, J., \& Inhelder, B. (1968). A Psicologia da Criança (Child Psychology). São Paulo Difel. (In Portuguese)

Rossetti, C. B., \& Missawa, D. D. (2008). Desempenho de crianças com e sem dificuldade de atenção no jogo Mancala (Performance of Children with and without Attention Difficulties in Mancala Games). Arquivos brasileiros de psicologia, 60, 60-74.

Torres, M. Z. (2001). Teenagers' Development and Learning Processes at Game Workshops. São Paulo: IPUSP. (In Portuguese)

Submit or recommend next manuscript to SCIRP and we will provide best service for you:

Accepting pre-submission inquiries through Email, Facebook, LinkedIn, Twitter, etc. A wide selection of journals (inclusive of 9 subjects, more than 200 journals)

Providing 24-hour high-quality service

User-friendly online submission system

Fair and swift peer-review system

Efficient typesetting and proofreading procedure

Display of the result of downloads and visits, as well as the number of cited articles

Maximum dissemination of your research work

Submit your manuscript at: http://papersubmission.scirp.org/

Or contact psych@scirp.org 